CLINICAL UTILITY GENE CARD UPDATE

\title{
Clinical utility gene card for: Trimethylaminuria - update 2014
}

\author{
Elizabeth A Shephard ${ }^{\star, 1}$, Eileen P Treacy ${ }^{2,3}$ and Ian R Phillips ${ }^{\star, 1,4}$ \\ European Journal of Human Genetics (2015) 23, doi:10.1038/ejhg.2014.226; published online 22 October 2014
}

Update to: European Journal of Human Genetics (2012) 20, doi:10.1038/ejhg.2011.214; published online 30 November 2011

\section{DISEASE CHARACTERISTICS}

1.1 Name of the disease (synonyms)

Trimethylaminuria (fish odour syndrome, fish malodour syndrome, stale fish syndrome).

\subsection{OMIM\# of the disease} 602079 .

1.3 Name of the analysed genes or DNA/chromosome segments FMO3.

\subsection{OMIM\# of the gene(s)}

136132.

\subsection{Mutational spectrum}

More than 30 sequence variants of the FMO3 gene have been reported to cause trimethylaminuria. Most are missense variants, but nonsense variants, small (1- or 2- bp) deletions and one large (12.2- kb) deletion have been reported. Variant descriptions reported here are on the basis of the genomic reference sequence NG_012690.1 and the transcript reference sequence NM_001002294.2. Causative sequence variants are population specific. The most common identified to date are c.458C > T (p. (Pro153Leu) $)^{1}$ and c.913G $>$ T (p. $\left(\right.$ Glu305 $\left.\left.{ }^{\star}\right)\right){ }^{2}$ in individuals of European ethnicity, and c.613C $>$ T $(p .(\operatorname{Arg} 205 \mathrm{Cys}))^{3}$ and c.1498C > T (p. $\left.\left(\operatorname{Arg} 500^{*}\right)\right),{ }^{4}$ in Japanese. In one case, the haplotype in which a variant occurs is important: c.560T $>\mathrm{C}$ (p.(Val187Ala)) has no effect on FMO3 activity, but when it occurs in cis with the common polymorphic variant c.472G $>$ A (p.(Glu158Lys)) it severely affects enzyme activity. ${ }^{5}$ A human FMO3 database has been established $^{6}$ (http://databases.lovd.nl/shared/genes/FMO3) and causative sequence variants identified to date have been reported. ${ }^{7-9}$ In addition to rare causative variants, 15 nonsynonymous singlenucleotide polymorphic (SNP) variants of FMO3 have been identified. ${ }^{10}$ Of these, only one, c.183C $>$ A (p.(Asn61Lys)), which occurs at low frequency, results in a severe reduction of enzyme activity. ${ }^{11}$ However, some polymorphic variants, for example, c.472G $>$ A (p.(Glu158Lys)) and c.923A $>$ G (p.(Glu308Gly)), when present in cis, can cause a moderate decrease in enzyme activity. ${ }^{10,12}$ When present in the homozygous state, they may cause mild or transient trimethylaminuria, particularly in infants and young children, ${ }^{13,14}$ who have low expression of FMO3. ${ }^{15}$ Two FMO3 haplotypes that contain promoter-region SNP variants have been reported to severely reduce expression in vitro. ${ }^{16}$ Although the impact of these haplotypes in vivo has not been validated, it is possible that they contribute to the disorder in the absence of coding-region variants. Four other haplotypes moderately reduce expression in vitro, ${ }^{17}$ a consequence of the presence of a g. $-5109 \mathrm{G}>\mathrm{C}$ SNP variant. Although none of the four haplotypes has a marked effect on the metabolism of trimethylamine (TMA) in vivo, ${ }^{17}$ it is possible that they contribute to more moderate forms of the disorder.

\subsection{Analytical methods}

The most common method is amplification of the eight coding exons, ${ }^{18}$ by PCR with exon-specific primers, followed by DNA sequencing of the amplicons. Large deletions are rare, being identified in only one individual, ${ }^{19}$ and can be identified by multiplex ligationdependent probe amplification.

\subsection{Analytical validation}

Both strands of DNA should be sequenced. Identified sequence variants should be compared with databases and the literature to establish whether they correspond to known causative variants. If a novel variant is found, then it is important to establish that it abolishes or substantially reduces the ability of $\mathrm{FMO} 3$ to catalyse the $\mathrm{N}$-oxygenation of trimethylamine, as assessed by assay of heterologously expressed variant protein. ${ }^{1,20,21}$ If an individual is heterozygous for two different causative sequence variants, then analysis of the parents' DNA will establish whether the variants are in trans. If an individual is homozygous or compound heterozygous ${ }^{22}$ for loss-of-function variants of FMO3, then diagnosis is confirmed.

1.8 Estimated frequency of the disease (incidence at birth ('birth prevalence') or population prevalence)

For severe, inherited trimethylaminuria, the incidence of heterozygous carriers in the white British population is $0.5-1.0 \%{ }^{23}$ The frequency of the severe type of the disorder in this population could thus be as high as 1 in 40000 . The true prevalence of the disorder is unknown; however, of patients referred to a malodour clinic in Philadelphia, $35 \%$ had trimethylaminuria. ${ }^{24}$

\footnotetext{
${ }^{1}$ Institute of Structural and Molecular Biology, University College London, London, UK; ${ }^{2}$ National Centre for Inherited Metabolic Disorders, Children's University Hospital, Dublin, Ireland; ${ }^{3}$ Trinity College, Dublin, Ireland; ${ }^{4}$ School of Biological and Chemical Sciences, Queen Mary University of London, London, UK

*Correspondence: Professor EA Shephard or Professor IR Phillips, Institute of Structural and Molecular Biology, University College London, Gower Street, London WC1E 6BT, UK. Tel: +44 207679 2321; Fax: +44 207679 7193; E-mail: e.shephard@ucl.ac.uk or i.r.phillips@ucl.ac.uk

Received 4 July 2014; revised 26 August 2014; accepted 19 September 2014
} 
1.9 If applicable, prevalence in the ethnic group of the investigated person

The incidence of heterozygous carriers is higher in the other ethnic groups studied: $1.7 \%$ in Jordanian, $3.8 \%$ in Ecuadorian and $11.0 \%$ in New Guinean populations, ${ }^{25}$ suggesting the frequency of the disorder may be as high as 1 in 3000 and 1 in 400 in the latter two groups, respectively.

\subsection{Diagnostic setting}

A. (Differential) diagnostics

B. Predictive testing

C. Risk assessment in relatives

D. Prenatal

\section{Comment:}

Trimethylaminuria usually presents with a body odour resembling that of rotten or decaying fish, the result of excess excretion of TMA in the breath, sweat, urine and reproductive fluids. ${ }^{26-29}$ Individuals complaining of or exhibiting a fishy odour should be tested for urinary excretion of TMA, ideally on two separate occasions. Genetic testing should be offered to individuals who, under normal dietary conditions, excrete more than $10 \%$ of total TMA as the free amine. Molecular diagnosis can identify affected individuals and heterozygous carriers. It can also distinguish primary genetic trimethylaminuria (including severe presentations, caused by loss-of-function variants of FMO3, and milder presentations, commonly resulting from compound heterozygozity for milder missense variants and polymorphic variants that affect FMO3 activity) from other, less common forms of trimethylaminuria such as the following:

1. An intermittent form, associated with menstruation, ${ }^{30,31}$ probably related to decreased expression of FMO3 in response to steroid hormones. The effect is more pronounced in women homozygous for combinations of polymorphic variants that affect FMO3 activity. ${ }^{31}$

2. A rare transient childhood presentation, as a consequence of immature FMO3 expression, which is switched on after birth and increases with age; ${ }^{15}$ young children who are heterozygous for a loss-of-function variant or have certain combinations of polymorphic variants of FMO3 may exhibit mild symptoms of the disorder, which disappear with age. ${ }^{13,14,32}$

3. Unusually, as a consequence of viral hepatitis, liver disease, or a major transient overload of dietary precursors of TMA with the coexistence of function-altering polymorphic variants of FMO3.

Prenatal diagnosis is possible if the disease-causing variants in the family have been identified.

\section{TEST CHARACTERISTICS}

\begin{tabular}{|c|c|c|c|c|}
\hline & \multicolumn{2}{|c|}{ Genotype or disease } & \multirow{2}{*}{$\begin{array}{l}\text { A: True positives } \\
\text { B: False positives }\end{array}$} & \multirow{2}{*}{$\begin{array}{l}\text { C: False negative } \\
D: \text { True negative }\end{array}$} \\
\hline & Present & Absent & & \\
\hline \multicolumn{5}{|l|}{ Test } \\
\hline Positive & A & B & $\begin{array}{l}\text { Sensitivity: } \\
\text { Specificity: }\end{array}$ & $\begin{array}{l}A /(A+C) \\
D /(D+B)\end{array}$ \\
\hline Negative & C & $\mathrm{D}$ & $\begin{array}{l}\text { Positive predictive value: } \\
\text { Negative predictive value: }\end{array}$ & $\begin{array}{l}A /(A+B) \\
D /(C+D)\end{array}$ \\
\hline
\end{tabular}

\subsection{Analytical sensitivity}

(proportion of positive tests if the genotype is present)

It is estimated that $99 \%$ of coding-region FMO3 variants may be detected by sequence analysis.

\subsection{Analytical specificity \\ (proportion of negative tests if the genotype is not present) \\ Insufficient data to comment.}

\subsection{Clinical sensitivity}

(proportion of positive tests if the disease is present)

The clinical sensitivity can be dependent on variable factors such as age or family history. In such cases, a general statement should be given, even if a quantification can only be made case by case.

Unknown. However, molecular genetic tests should distinguish between variants that abolish or severely affect FMO3 activity and, thus, cause severe primary trimethylaminuria, from those that have a relatively moderate effect, resulting in mild or transient forms of the disorder. But acquired and secondary forms of trimethylaminuria, which are not caused by sequence variants, would not give a positive genetic test.

Genotype analysis of 78 Japanese who tested positive for trimethylaminuria by urinary analysis revealed that 10 of the 13 diagnosed as severe were homozygous or compound heterozygous for known causative sequence variants. ${ }^{17}$ Given the severity of their phenotypes, it is likely that the other three, who had no coding-region causative variants, have unidentified variants elsewhere in the FMO3 gene that severely affect transcription or RNA processing. Of the 65 individuals classified as moderate or mild cases, none was homozygous or compound heterozygous for causative variants and, thus, suffer from secondary forms of the disorder. ${ }^{17}$ Most of the moderate or mild cases were not a consequence of TMA overload but of a compromised ability to metabolize TMA to TMA $N$-oxide, ${ }^{17}$ possibly due to the presence of unidentified sequence variants that have moderate effects on transcription or RNA processing, or due to inhibition of FMO3 activity, for instance, by posttranslational modification via nitric oxidemediated $S$-nitrosylation. ${ }^{33}$

\subsection{Clinical specificity}

(proportion of negative tests if the disease is not present)

The clinical specificity can be dependent on variable factors such as age or family history. In such cases a general statement should be given, even if a quantification can only be made case by case.

Only individuals who have tested positive for trimethylaminuria by urinary analysis, or their relatives, will be genetically tested.

\subsection{Positive clinical predictive value}

(life-time risk to develop the disease if the test is positive)

All those identified as homozygous or compound heterozygous for sequence variants that abolish or severely impair FMO3 activity suffer from the primary genetic form of the disorder and display symptoms of severe trimethylaminuria.

\subsection{Negative clinical predictive value} (probability not to develop the disease if the test is negative)

Assume an increased risk based on family history for a non-affected person. Allelic and locus heterogeneity may need to be considered.

Index case in that family had been tested:

Close to $100 \%$ if known causative sequence variants have been identified in the index patient. 
Index case in that family had not been tested:

Unknown. Only patients that present with symptoms are analysed.

\section{CLINICAL UTILITY}

3.1 (Differential) diagnostics: The tested person is clinically affected (To be answered if in 1.10 'A' was marked)

\subsubsection{Can a diagnosis be made other than through a genetic test?}

\begin{tabular}{ll}
\hline No & $\square$ (continue with 3.1.4) \\
Yes & $\square$ \\
& Clinically \\
Imaging & \\
& Endoscopy \\
& Biochemistry \\
& Electrophysiology \\
& Other (please describe):
\end{tabular}

Clinically: trimethylaminuria is characterized by a body odour resembling that of rotten or decaying fish. However, diagnosis based on smell is unreliable: the odour is often episodic, it may be caused by chemicals other than TMA, and not all individuals can detect the smell of TMA. ${ }^{34}$ Note: On the basis of smell, trimethylaminuria can be difficult to distinguish from other conditions that give rise to an unpleasant body odour, including poor hygiene, forms of gingivitis and blood-borne halitosis, ${ }^{35}$ or the rare inherited metabolic disorder dimethylglycinuria, caused by a deficiency of dimethylglycine dehydrogenase. ${ }^{36}$

Biochemistry: diagnosis is based on the percent of total TMA (free TMA plus the non-odorous TMA $\mathrm{N}$-oxide) excreted in the urine as the unmetabolized free amine $8,29,37$

— $>40 \%$ : severe trimethylaminuria

-10-39\%: mild trimethylaminuria $-<10 \%$ : unaffected

Note: Urinary tract infections, bacterial vaginosis, advanced liver or kidney disease and cervical cancer can result in large amounts of TMA in the urine. But, in contrast to the inherited form of trimethylaminuria, in these cases the TMA/TMA $\mathrm{N}$-oxide ratio is normal.

To distinguish transient or episodic forms of trimethylaminuria from the primary inherited form, biochemical testing should be performed on two separate occasions. Unaffected women may have a short episode of trimethylaminuria at the onset of and during menstruation, ${ }^{31}$ so females should not be tested during this time. Because of the importance of intestinal bacteria in the production of TMA from dietary precursors, variations in intestinal microbiota might affect the results of the diagnostic test. Under normal dietary conditions, heterozygotes cannot be distinguished from unaffected individuals. ${ }^{37}$ However, heterozygous carriers can be detected after administration of a 'TMA load' of $600 \mathrm{mg}$, given orally in a gelatine capsule. ${ }^{26,38}$

\subsubsection{How is the cost effectiveness of alternative diagnostic methods to} be judged?

The initial diagnosis of trimethylaminuria is usually biochemical. Genetic testing will help to confirm the diagnosis, distinguish the various genetic and non-genetic forms of the disorder and identify asymptomatic heterozygous carriers.

\subsubsection{Will disease management be influenced by the result of a genetic test?}

\begin{tabular}{ll}
\hline No & $\square$ \\
Yes & $\square$ \\
& Therapy (please \\
& describe)
\end{tabular}

Strategies for treatment of the disorder 8,37 and bestpractice guidelines ${ }^{28,39}$ have been published. In general, the greater the effect of a sequence variant on the activity of FMO3, the more severe the symptoms and the less responsive the individual will be to treatment. The main treatment strategy is dietary restriction of precursors of TMA, including choline, lecithin and TMA $\mathrm{N}$-oxide. Choline is present in high amounts in some foods such as eggs, offal (liver, kidney), peas, beans, peanuts and soya products. Brassica vegetables (such as Brussels sprouts, broccoli, cabbage and cauliflower) are thought to inhibit FMO activity, thus intake should be minimized. TMA N-oxide is present in seafood. Choline is essential in the foetus and in young infants for nerve and brain development, and should not be over restricted in infants, children and pregnant or lactating women. Nutritionally balanced, choline-restricted diets suitable for treatment of the disorder have been developed. ${ }^{40}$ Individuals with mild or moderate forms of the disorder usually respond well.

For individuals who respond poorly to diet, a step-wise approach to other therapies should be instituted. Intermittent brief courses of antibiotics such as metronidazole used cautiously (eg, perimenstrually in females or for stressful social occasions) have been found to be effective. ${ }^{39,41,42}$ In the case of sequence variants that do not completely abolish FMO3 activity, supplements of riboflavin, a precursor of the FAD prosthetic group of FMO3, might help maximize residual enzyme activity. ${ }^{43}$ At present, there is only anecdotal evidence of efficacy and oral riboflavin supplementation requires careful monitoring because gastrointestinal intolerance can occur, especially in children. Other forms of treatment are aimed at sequestering TMA produced in the gut, by taking dietary supplements of copper chlorophyllin or activated charcoal. ${ }^{44}$

Prognosis (please Affected individuals appear normal and healthy. No describe) physical symptoms are associated with trimethylaminuria, but the unpleasant body odour characteristic of the disorder often results in social and psychological problems, $8,26,45$ which can have serious effects on personal and working lives. These may include: — In childhood, being shunned, ridiculed or bullied at school, leading to aggressive or disruptive behaviour and poor educational performance.

-A sense of shame or embarrassment, leading to low self-esteem and reluctance to seek medical help. -Avoidance of contact with people, leading to social isolation, loneliness, frustration and depression. -Difficulties in initiating or maintaining relationships. — In extreme cases, paranoid behaviour, desperation and suicidal tendencies.

\subsubsection{Describe the burden of alternative diagnostic methods to the patient}

Very low. However, one individual developed an adverse reaction, with fever and vomiting, after a choline challenge. ${ }^{39}$ 
For individuals with primary genetic trimethylaminuria, symptoms are usually present from birth.

The condition may worsen during puberty and, in females, is more severe just before and during menstruation, after taking oral contraceptives and around menopause. Treatment and dietary management may alleviate symptoms in some, but not all, individuals.

Management (please Affected individuals should avoid:

describe)

\begin{abstract}
1. Foods with a high content of precursors of TMA or
\end{abstract} inhibitors of FMO3 activity; for instance, eggs, offal (liver and kidney), legumes, brassicas, soya products and seafood (fish, crustaceans and cephalopods) should be avoided or eaten in moderation. Freshwater fish are not a problem.

2. Drugs that are metabolized by FMO3, which will exacerbate the condition by competition for residual FMO3 activity and may cause adverse effects. Examples include the antipsychotic clozapine, the monoamine oxidase inhibitor deprenyl, the anti-histamine ranitidine, the anti-oestrogen tamoxifen and the anti-inflammatories sulindac and benzydamine. ${ }^{10}$

3. Food supplements and 'health' foods that contain high amounts of choline and lecithin.

4. Factors that promote sweating, such as fever, exercise, stress and emotional upsets.

TMA is a strong base (pKa 9.8). Thus, at pH 6.0,

$<0.02 \%$ of TMA exists as the volatile free base. The use of soaps and body lotions with a pH close to that of normal skin ( $\mathrm{pH}$ 5.5-6.5) helps retain secreted TMA in a less-volatile salt form that can be removed by washing. ${ }^{46}$

3.2 Predictive setting: the tested person is clinically unaffected but carries an increased risk based on family history

(To be answered if in 1.10 'B' was marked)

3.2.1 Will the result of a genetic test influence lifestyle and prevention?

If the test result is positive (please describe):

Not applicable.

If the test result is negative (please describe):

Not applicable.

3.2.2 Which options in view of lifestyle and prevention does a person at-risk have if no genetic test has been done (please describe)? Not applicable.

3.3 Genetic risk assessment in family members of a diseased person (To be answered if in 1.10 ' $C$ ' was marked)

\subsubsection{Does the result of a genetic test resolve the genetic situation in that family?}

A genetic test should distinguish primary inherited and secondary forms of trimethylaminuria, mild and severe forms of the inherited disorder and identify heterozygous carriers.

\subsubsection{Can a genetic test in the index patient save genetic or other tests} in family members?

The parents and offspring of an individual affected by primary inherited trimethylaminuria will be obligate heterozygotes. Sibs of an affected individual would have to be genetically tested to establish whether they were affected, unaffected or a heterozygous carrier.
3.3.3 Does a positive genetic test result in the index patient enable a predictive test in a family member?

Not applicable.

\subsection{Prenatal diagnosis}

(To be answered if in 1.10 'D' was marked)

\subsubsection{Does a positive genetic test result in the index patient enable a} prenatal diagnosis?

Yes, but it is not indicated.

\section{IF APPLICABLE, FURTHER CONSEQUENCES OF TESTING}

Please assume that the result of a genetic test has no immediate medical consequences. Is there any evidence that a genetic test is nevertheless useful for the patient or his/her relatives? (Please describe)

Affected individuals and their families benefit from counselling. Realization that the problem is the result of a recognized medical condition may help.

\section{CONFLICT OF INTEREST}

The authors declare no conflict of interest.

\section{ACKNOWLEDGEMENTS}

This work was supported by CIBERER, EuroGentest2 (unit 2: 'Genetic testing as part of health care'), a Coordination Action under FP7 (grant agreement number 261469) and the European Society of Human Genetics.

1 Dolphin CT, Janmohamed A, Smith RL, Shephard EA, Phillips IR: Missense mutation in flavin-containing mono-oxygenase 3 gene, FMO3, underlies fish-odour syndrome. Nat Genet 1997; 17: 491-494.

2 Treacy EP, Akerman BR, Chow LML et al: Mutations of the flavin-containing monooxygenase gene (FMO3) cause trimethylaminuria, a defect in detoxication. Hum Mol Genet 1998; 7: 839-845.

3 Fujieda M, Yamazaki H, Togashi M, Saito T, Kamataki T: Two novel single nucleotide polymorphisms (SNPs) of the FMO3 gene in Japanese. Drug Metab Pharmacokinet 2003; 18: 333-335.

4 Yamazaki H, Fujita H, Gunji T et al: Stop codon mutations in the flavin-containing monooxygenase 3 (FMO3) gene responsible for trimethylaminuria in a Japanese population. Mol Genet Metab 2007; 90: 58-63.

5 Motika MS, Zhang J, Zheng X, Riedler K, Cashman JR: Novel variants of the human flavin-containing monooxygenase 3 (FMO3) gene associated with trimethylaminuria. Mol Genet Metab 2009; 97: 128-135.

6 Hernandez D, Addou S, Lee D, Orengo C, Shephard EA, Phillips IR: Trimethylaminuria and a human FMO3 mutation database. Hum Mutat 2003; 22 209-213.

7 Phillips IR, Shephard EA: Flavin-containing monooxygenases: mutations, disease and drug response. Trends Pharmacol Sci 2008; 29: 294-301.

8 Phillips IR, Shephard EA: Trimethylaminuria. GeneReviews at GeneTests: Medical Genetics Information Resource (database online). University of Washington, Seattle, WA, USA, 1997-2011. Available at http://www.ncbi.nlm.nih.gov/books/NBK1103/ (updated 2011).

9 Yamazaki H, Shimizu M: Survey of variants of human flavin-containing monooxygenase 3 (FMO3) and their drug oxidation activities. Biochem Pharmacol 2013; 85: 1588-1593.

10 Phillips IR, Francois AA, Shephard EA: The flavin-containing monoooxygenases (FMOs): genetic variation and its consequences for the metabolism of therapeutic drugs. Curr Pharmacogenomics 2007; 5: 292-313.

11 Koukouritaki SB, Poch MT, Henderson MC et al: Identification and functional analysis of common human flavin-containing monooxygenase 3 genetic variants. J Pharmaco Exp Ther 2007; 320: 266-273.

12 Koukouritaki SB, Hines RN: Flavin-containing monooxygenase genetic polymorphism: impact on chemical metabolism and drug development. Pharmacogenomics 2005; 6 : 807-822.

13 Zschocke J, Kohlmueller D, Quak E, Meissner T, Hoffmann GF, Mayatepek E: Mild trimethylaminuria caused by common variants in FMO3 gene. Lancet 1999; 354: 834-835.

14 Zschocke J, Mayatepek E: Biochemical and molecular studies in mild flavin monooxygenase 3 deficiency. J Inherit Metab Dis 2000; 23: 378-382.

15 Koukouritaki SB, Simpson P, Yeung CK, Rettie AE, Hines RN: Human hepatic flavincontaining monooxygenases 1 (FMO1) and 3 (FMO3) developmental expression. Pediatr Res 2002; 51: 236-243. 
16 Koukouritaki SB, Poch MT, Cabacungan ET, McCarver DG, Hines RN: Discovery of novel flavin-containing monooxygenase 3 (FMO3) single nucleotide polymorphisms and functional analysis of upstream haplotype variants. Mol Pharmacol 2005; 68: 383-392.

17 Shimizu M, Allerston CK, Shephard EA, Yamazaki H, Phillips IR: Relationship between flavin-containing mono-oxygenase 3 (FMO3) genotype and trimethylaminuria phenotype in a Japanese population. Brit J Clin Pharmacol 2014; 77: 839-851.

18 Dolphin CT, Riley JH, Smith RL, Shephard EA, Phillips IR: Structural organization of the human flavin-containing monooxygenase 3 gene (FMO3), the favoured candidate for fish-odor syndrome, determined directly from genomic DNA. Genomics 1997; 46: 260-267.

19 Forrest SM, Knight M, Akerman BR, Cashman JR, Treacy EP: A novel deletion in the flavin-containing monooxygenase gene (FMO3) in a Greek patient with trimethylaminuria. Pharmacogenetics 2001; 11: 169-174.

20 Murphy HC, Dolphin CT, Janmohamed A et al: A novel mutation in the flavin-containing monooxygenase 3 gene, $\mathrm{FMO3}$, that causes fish-odour syndrome: activity of the mutant enzyme assessed by proton NMR spectroscopy. Pharmacogenetics 2000; 10 : 439-451.

21 Allerston CK, Vetti HH, Houge G, Phillips IR, Shephard EA: A novel mutation in the flavin-containing monooxygenase 3 gene (FMO3) of a Norwegian family causes trimethylaminuria. Mol Genet Metab 2009; 98: 198-202.

22 Dolphin CT, Janmohamed A, Smith RL, Shephard EA, Phillips IR: Compound heterozygosity for missense mutations in the flavin-containing monooxygenase 3 (FM03) gene in patients with fish-odour syndrome. Pharmacogenetics 2000; 10: 799-807.

23 Al-Waiz M, Ayesh R, Mitchell SC, Idle JR, Smith RL: A genetic polymorphism of the $\mathrm{N}$-oxidation of trimethylamine in humans. Clin Pharmacol Ther 1987; 42: 588-594.

24 Wise PM, Eades J, Tjoa S, Fennessey PV, Preti G: Individuals reporting idiopathic malodor production: demographics and incidence of trimethylaminuria. Am J Med 2011; 124: 1058-1063.

25 Mitchell SC, Zhang AQ, Barrett T, Ayesh R, Smith RL: Studies on the discontinuous $\mathrm{N}$-oxidation of trimethylamine among Jordanian, Ecuadorian and New Guinean populations. Pharmacogenetics 1997; 7: 45-50.

26 Mitchell SC, Smith RL: Trimethylaminuria: the fish malodor syndrome. Drug Metab Dispos 2001; 29: 517-521.

27 Mitchell S: Trimethylaminuria (fish-odour syndrome) and oral malodour. Oral Dis 2005; 11 (Suppl 1): 10-13.

28 Treacy EP: Trimethylaminuria and Deficiency of Flavin-Containing Monooxygenase Type 3 (FMO3). New York, NY, USA: McGraw-Hill, 2007, Chapter 88.1. www.ommbid.com.

29 Mackay RJ, McEntyre CJ, Henderson C, Lever M, George PM: Trimethylaminuria: causes and diagnosis of a socially distressing condition. Clin Biochem Rev 2011; 32 33-43.
30 Zhang $A Q$, Mitchell SC, Smith RL: Exacerbation of symptoms of fish-odour syndrome during menstruation. Lancet 1996; 348: 1740-1741.

31 Shimizu M, Cashman JR, Yamazaki H: Transient trimethylaminuria related to menstruation. BMC Med Genet 2007; 8: 2.

32 Mayatepek E, Kohlmüller D: Transient trimethylaminuria in childhood. Acta Paediatrica 1998; 87: 1205-1207.

33 Ryu SD, Yi HG, Cha YN et al: Flavin-containing monooxygenase activity can be inhibited by nitric oxide-mediated S-nitrosylation. Life Sci 2004; 75: 2559-2572.

34 Heaton P: Ability to detect malodour might be genetic [letter; comment]. BMJ 1993; 307: 1009.

35 Tangerman A: Halitosis in medicine: a review. Int Dent J 2002; 52 (Suppl 3): 201-206.

36 Binzak BA, Wevers RA, Moolenaar SH et al: Cloning of dimethylglycine dehydrogenase and a new human inborn error of metabolism, dimethylglycine dehydrogenase deficiency. Am J Hum Genet 2001; 68: 839-847.

37 Cashman JR, Camp K, Fakharzadeh SS et al: Biochemical and clinical aspects of the human flavin-containing monooxygenase form 3 (FMO3) related to trimethylaminuria. Curr Drug Metab 2003; 4: 151-170.

38 Al-Waiz M, Ayesh R, Mitchell SC, Idle JR, Smith RL: Trimethylaminuria: the detection of carriers using a trimethylamine load test. J Inherit Metab Dis 1989; 12: 80-85.

39 Chalmers RA, Bain MD, Michelakakis H, Zschocke J, Iles RA: Diagnosis and management of trimethylaminuria (FM03 deficiency) in children. J Inherit Metab Dis 2006; 29: $162-172$

40 Busby MG, Fischer L, da Costa KA, Thompson D, Mar MH, Zeisel SH: Choline- and betaine-defined diets for use in clinical research and for the management of trimethylaminuria. J Am Diet Assoc 2004; 104: 1836-1845.

41 Treacy E, Johnson D, Pitt JJ, Danks DM: Trimethylaminuria, fish odour syndrome: a new method of detection and response to treatment with metronidazole. J Inherit Metab Dis 1995; 18: 306-312.

42 Fraser-Andrews EA, Manning NJ, Ashton GH, Eldridge P, McGrath J, Menage Hdu P: Fish odour syndrome with features of both primary and secondary trimethylaminuria. Clin Exp Dermatol 2003; 28: 203-205.

43 Manning NJ, Allen EK, Kirk RJ, Sharrard MJ, Smith EJ: Riboflavin-responsive trimethylaminuria in a patient with homocystinuria on betaine therapy. JIMD Rep 2012; 5: 71-75.

44 Yamazaki H, Fujieda M, Togashi M: Effects of the dietary supplements, activated charcoal and copper chlorophyllin, on urinary excretion of trimethylamine in Japanese trimethylaminuria patients. Life Sci 2004; 74: 2739-2747.

45 Todd WA: Psychosocial problems as the major complication of an adolescent with trimethylaminuria. J Pediatr 1979; 94: 936-937.

46 Wilcken B: Acid soaps in the fish odour syndrome. Br J Med 1993; 307: 1497. 